United Nations Development Program (2016) About Sierra Leone. Retrieved from: http://www.sl.undp.org/content/sierraleone/en/home/ countryinfo.html.

West C., Bernard B., Mueller C., et al (2008) Mental health outcomes in police personnel after Hurricane Katrina. Journal of Occupational and Environmental Medicine, 50(6), 689-695.

Whitfield G. (2010) Group cognitive-behavioural therapy for anxiety and depression. Advances in Psychiatric Treatment, 16(3), 219-227.
World Health Organisation (WHO) (2010). mhGAP Intervention Guide for Mental, Neurological and Substance Use Disorders in Non Specialized Health Settings: Mental Health Gap Action Programme (mhGAP). Retrieved from: www.who.int/mental_health/mhgap.

Yoldi O. (2012) Sierra Leone: Trapped in the Shadows of the Mind. Refugee Transitions, 26, 60-65. Retrieved from: http:/ /www.startts. org.au/media/Refugee-Transitions/

Refugee-Transitions-Issue-26-sierra-leone-trapped-in-theshadows-of-the-mind.pdf

\title{
EDITORIAL \\ Global mental health and sustainable development 2018
}

\author{
Rachel Jenkins ${ }^{1,2}$
}

\section{${ }^{1}$ Institute of Psychiatry, Psychology and Neuroscience, King's College London, UK \\ ¿BA (Hons), MB, BChir, MD (Cantab), Institute of Psychiatry, Health Services Research, de Crespigny Park, London SE5 8AF, UK. Email: rachel@olan.org}

Conflicts of interest None.

Keywords. Global mental health; sustainability; service users: mental health services; integrated service provision.

\section{doi:10.1192/bji.2019.5}

c The Author 2019. This is an Open Access article, distributed under the terms of the Creative Commons AttributionComs AtributionCom cence (http://creativecommons. org/licenses/by-nc-nd/4.0/), which permits non-commercial re-use, distribution, and reproduction in any medium, provided the original work is unaltered and is preper mission of Cambridge University Press must be obtained for com mercial re-use or in order to create a derivative work.

\begin{abstract}
The Lancet Commission summarises some of the history of mental health concepts, recent developments in scientific understanding, mental health programmes and threats to progress, and proposes a way forward. Although ostensibly aiming to reframe global mental health within the paradigm of sustainable development, in practice it has taken a narrower academic perspective rather than a generic approach to health and social sector reform, leading to much less of an integrated implementation focus than would have been useful.
\end{abstract}

Three years ago, the UN launched its Sustainable Development Goals (SDGs) to push world leaders into addressing problems such as poverty, hunger and climate change (UN, 2015). The SDGs replaced the earlier Millennium Development Goals (MDGs). These had not specifically included mental health (UN, 2000), although mental health was critically relevant to most of the MDGs, especially those relating to physical health, education and economic development (Gureje \& Jenkins, 2007).

The importance of mental health as an integral part of health in general has long been recognised (WHO, 1946). It was reaffirmed with the Declaration of Alma-Ata (WHO, 1978) that affirmed, for the first time, the critical role of primary healthcare for all. The early establishment of the World Health Organization (WHO) Mental Health Division and the World Federation of Mental Health in 1948 paved the way for attention to global mental health via research, policy, training and advocacy over subsequent decades. Calls for enhanced action on mental health have continued since that time, most visibly by the establishment of World Mental Health Day (10 October), initiated by Mrs Roslyn Carter (wife of the ex-US President Jimmy Carter), which has been celebrated in most countries every year since 1992 .
Unlike the earlier MDGs, the recently published SDGs specifically include mental health. (Box 1). They provide a useful framework for stimulating, monitoring and reviewing global development. The Lancet took the opportunity to produce a Commission on Global Mental Health and Sustainable Development, with a view to assessing the agenda and progress in the context of the SDGs. The report of the Commission contains much of interest to a wide audience. It gives some perspectives on the history of mental health concepts, on recent developments in scientific understanding and on mental health programmes; it assesses threats to progress, including human rights abuses, constrained resources, major demographic transitions and social risk factors; and it emphasises the importance of addressing mental

Box 1. The mental health-related SDGs

$S D G 3.4$ requires states to adopt the following aim: 'By 2030, (to) reduce by one third premature mortality from non-communicable disease (NCDs) through prevention and treatment and promote mental health and well-being'. SDG 3.5 requires states to 'strengthen the prevention and treatment of substance abuse, including narcotic drug abuse and harmful use of alcohol'. Thus, SDG 3.5 and the first part of SDG 3.4 demand policy attention for the prevention and treatment of mental, neurological and substance use disorders, while the second half of SDG 3.4 requires policy attention to be given to mental health promotion.

Other SDGs (especially 1,5, 8 and 10, relating to poverty reduction, gender, economic development and reducing inequalities, respectively) also require attention be paid to mental health, as mental disorders are highly associated with poverty, financial hardship and debt, and low productivity. They are generally more common in women, among ethnic minorities, people with disabilities and other marginalised groups (Foresight 2008; Beddington et al, 2008). 
health promotion and prevention, as well as treatment, rehabilitation and care. Headline approaches to improving global mental health include: (a) the scaling up of mental health services as an essential component of universal health coverage; (b) addressing barriers and threats to mental health; (c) the protection of mental health by public policies; (d) the embracing of new technologies; (e) additional financial investment; and (f) more research and innovation.

Although it claims to be comprehensive in coverage, the Commission fails to cite a number of highly significant reports that are of continuing value, including the following: (a) an Institute of Medicine report (Institute of Medicine, 2001), which resulted in greatly increased US funding for research on mental and neurological disorders; (b) the Foresight Report (2008) on mental capital and well-being, which provided the rationale for governments to value and invest in the positive mental health of their populations, focusing on the need to address mental disorders and arguing for a systematic life course approach to identifying need, an approach that is widely heeded and was used by the Lancet Commission itself; (c) the UN (1996) report on suicide prevention, which has underpinned national strategies for suicide prevention ever since; and (d) historic WHO implementation projects, which contain valuable lessons for today (e.g. Schulsinger \& Jablensky, 1991).

While the ostensible aim of the Commission was to reframe global mental health within the paradigm of sustainable development, in practice it has taken a narrow academic perspective rather than a generic approach to health and social sector reform. Therefore, it does not have as strong an implementation focus as it should have done. The recommendation that there should be 'scaling up of mental health services as an essential component of universal health coverage' implies a more specialist, vertical and indeed probably more costly approach than would the preferable phrase '(there should be) integration of mental health into universal health coverage'.

The clue to a better-focused response to the UN (2015) report is in the name - development needs to be sustainable and indeed sustained if the population is to benefit. In order to achieve the SDGs, governments must strengthen their health and social systems (WHO, 2007). We need to argue for the inclusion and integration of mental health within a broad system of health improvement that strengthens local and national initiatives, and we should rigorously review progress (Jenkins et al, 2019).

We need an approach to mental healthcare that works within health, social and other sector reform cycles (which generally recur every 5-10 years) with a view to integrating mental health at all levels. The Commission has unfortunately missed a valuable opportunity to examine the literature and on-the-ground experiences that are relevant to appropriate and adequate implementation of reforms to mental health services. Although it has recommended the introduction of national indicators of progress, this misses the point. For implementation to happen, data need to be collected and monitored at the grass roots level. The lack of relevant routine indicators at a primary care level remains a major barrier to local implementation, supervision and monitoring (Ndetei \& Jenkins, 2009; Jenkins et al, 2013).

The Lancet Commission on Mental Health call for global partnership is framed in a way that does not fit comfortably with how things work on the ground. It appears to be calling for vertical funding and programming. Its recommendations do not sit well with the need for national generic health system strengthening (Atun et al, 2015), nor with the need to avoid repeating past errors such as creating parallel funding systems and parallel delivery systems for physical and mental healthcare. Such unfortunate consequences were all too visible when a new pattern of administration was devised for the delivery of anti-retroviral drugs (ARVs) for HIV treatment. As it was initially separated from the existing local health delivery systems, there was a consequent lack of investment in primary and district-level care. Consequently, primary care and district health staff were tempted to take better-paid posts within the parallel ARV delivery system. It is better to work towards the integration of mental health into all generic funding programmes. Donors that support ministries of health with generic budgets should make explicit the expectation that mental health will be appropriately included, and integrated, at all levels of healthcare delivery. It should also be an integral part of education, social welfare and criminal justice budgets.

Countries are increasingly decentralising funding decisions about healthcare delivery. Priorities, staffing and budgets are becoming matters for decision-making at a local rather than a national level. Persistent advocacy has thus become crucial at local levels. Familiarity and expertise with planning processes should be part of the training curriculum for all mental health workers. They should be encouraged to influence local planning decisions (Jenkins et al, 2010a, 2010b).

Despite the Commission's historical reference to Engel's biopsychosocial model (George \& Engel, 1980), and their scientific appreciation of the multifactorial causation of mental illness, the authors of the report have missed a golden opportunity. They should have recommended that a systematic multiaxial approach be integrated into the training of all health workers, and into the assessment, diagnosis and management of all illness. There is a mass of evidence for the size and extent of the comorbidity between physical and mental illness. Not only is there shared symptomatology, a powerful influence is also exerted by environmental and social factors on both domains of ill health. In the absence of a systemic approach to care, there will be worse health and 
It is of critical importance to be aware of regional differences in the availability of acute beds to support community services. In many sub-Saharan African countries, the overall bed/population ratio is extremely low relative to the rest of the world. There may be one large mental hospital in the country, usually situated in, or on the edge of, the capital city. Situation appraisal usually reveals significant previous efforts to resettle long-stay patients with long-term mental disorders back into their local communities. Consequently, the proportion of long-stay patients is nowadays often low. Nevertheless, although long-stay bed occupancy rates might have fallen since earlier times, acute short-term admissions for acute psychosis, often with substance misuse as a comorbidity, have been rising as the population prevalence of substance misuse increases, and as the population of the capital city rapidly expands. The former national asylum is being transformed into the capital city's regional hospital. Its beds may be serving an urban population of several million people, as well as providing the only secure forensic unit in the country. Those beds could be redistributed to general hospitals, but this would require double funding for a significant period while planning, construction and staff training occurred. The redistribution would not be a quick fix for budgets. Meanwhile, additional funds would in any case be needed to develop small numbers of acute beds in each district around the country. In some countries, especially the states of the former Soviet Union, there are still many large mental hospitals and other institutions with a relatively high proportion of long-stay clients. Double funding would be required to shift those clients to local community-based comprehensive care. Simply closing the beds runs the risk of former patients being left unsupported, with the attendant risks of homelessness, which is especially dangerous in cold climates.

social outcomes and increasingly severe strains on any health system because of repeat consultations, misdiagnosis and mistreatment.

The Commission discusses risk factors for mental health disorders. Childhood adversity and financial strain are mentioned, but there is no specific recognition of the importance of childhood sexual abuse (Jonas et al, 2011). This is by far the strongest risk factor across the life course for mental disorder and suicide. It requires major policy action to enhance prevention. Nor is there any mention of unmanageable debt, which is a much stronger risk factor for mental and physical health than either low income or income inequality (Richardson et al, 2013). The Commission pays much attention to epigenetics and rather less to immunity, despite its significance not only in the pathogenesis of mental illness but also because of its association with physical disorders (e.g. Jenkins et al, 2018).

There are several practical barriers to the integration of mental health into universal health coverage that the Commission does not mention, but which need urgent global as well as national attention. For example, it does not address the international brain drain from low- and middle-income to much wealthier countries, which does catastrophic harm to their health systems (Jenkins et al., 2010a, 2010b; WHO, 2010; Jenkins, 2016). There is an interesting discussion of human rights issues. Yet no attention is paid to the practical difficulties of implementing mental health legislation in low-income countries; insufficient specialists are on hand to provide mental health act assessments or to provide reviews, and they often lack the necessary transport to enable such work (Bartlett et al, 2011).

The Commission calls for the transfer of budgets from large mental hospitals to local services. While this is ostensibly a laudable aim, the practicalities to ensure safe transition are complex, and double funding will be required for many years.
Otherwise, there is a risk of catastrophic harm (it is better to be realistic about this) (Box 2).

The Commission report evinces a frustrating lack of historical appreciation, stemming perhaps from self-congratulation. According to the authors, the 'global mental health movement' was initiated by a series of Lancet articles (Horton, 2007). It would have been better for the Commission to stand back and view the past 60 years or so with an eye to where the serious advances on the ground have actually taken place. Statements such as 'Civil society began to partner with mental health professionals to promote a shared vision, the most notable example being the Movement of Global Mental Health that launched in 2008 as a virtual global alliance' are simply misleading. It is arguable that by far the most far-reaching and sustained global alliance between mental health professionals and civil society was the World Federation of Mental Health, founded in 1948 (Brody, 2004). The claim that '... the 2007 Lancet Series ... propelled mental health into the global health spotlight...' ignores the fact that global mental health has been an agenda item for the WHO for decades. The WHO (2001) Annual Report was entirely devoted to mental health.

In the 1960s and 1970s, a large cadre of mental health nurses were trained and deployed in sub-Saharan Africa. They have provided the backbone of mental health specialist services in several countries for decades. Unfortunately, because of HIV, unaffordable course fees and the aforementioned brain drain, this workforce is becoming increasingly depleted. It is a pity the Commission did not acknowledge its historic establishment and has not called for its current maintenance and sustainability needs to be recognised and valued before it is lost. Providing mental healthcare in a global context is challenging and risks fractionalisation of services. Those who ignore history are condemned to repeat it! 


\section{References}

Atun R. (2015) Transitioning health systems for multimorbidity. Lancet, 386(9995), 721-2.

Bartlett P., Jenkins R. \& Kiima D. (2011) Mental health law in the community: thinking about Africa. International Journal of Mental Health Systems, 5, 21.

Beddington J., Cooper C., Field J., et al (2008) The mental wealth of nations. Nature, 445(7216), 1057-1060.

Brody E. B. (2004) The World Federation for Mental Health: its origins and contemporary relevance to WHO and WPA policies. World Psychiatry, 3(1), 54

Foresight Mental Capital and Wellbeing Project (2008) Final Project Report. The Government Office for Science (https://www.gov.uk/ government/uploads/system/uploads/attachment_data/file/292453/ mental-capital-wellbeing-summary.pdf).

George E. \& Engel L. (1980) The clinical application of the biopsychosocial model. American Journal of Psychiatry, 5, 535-544.

Gureje O. \& Jenkins R. (2007) Mental health in development: re-emphasising the link. Lancet, 369, 447-449.

Horton R. (2007) Launching a new movement for mental health. Lancet, 370(9590), 806

Institute of Medicine (2001) Neurological, Psychiatric, and Developmental Disorders: Meeting the Challenge in the Developing World. Committee on Nervous System Disorders, Board on Global Health, Institute of Medicine. National Academy Press.

Jenkins R. (2016) Brain drain. International Psychiatry, 13, 53-55.

Jenkins R. (2019) Strengthening government policy to achieve target 3.4. of SDG3. In Routledge Handbook of International Development, Mental Health and Wellbeing (ed. L. Davidson). Taylor \& Francis Group.

Jenkins R., Kydd R., Mullen P., et al (2010a) International migration of doctors, and its impact on availability of psychiatrists in low income countries. PLoS One, 5(2), e9049.

Jenkins R., Kiima D., Njenga F., et al (2010b) Integration of mental health into primary care in Kenya. World Psychiatry, 9(2), 118-120.

Jenkins R., Othieno C., Okeyo S., et al (2013) Health system challenges to integration of mental health delivery in primary care in Kenya - perspectives of primary care health workers. BMC Health Services Research, 13(1), 368.

Jenkins R., Ogeechee M., Othieno C., et al (2018) Malaria, mental disorders, immunity and their inter-relationships - a cross sectional study in a household population in a health and demographic surveillance site in Kenya. EBioMedicine, doi: 10.1016/j. ebiom.2018.11.064.

Jonas S., Bebbington P., McManus S., et al (2011) Sexual abuse and psychiatric disorder in England: results from the 2007 adult psychiatric morbidity survey. Psychological Medicine, 41(4), 709-719.

Ndeti D. M. \& Jenkins R. (2009) The implementation of mental health information systems in developing countries: challenges and opportunities. Epidemiologia e Psichiatria Sociale, 18(1), 12-16.

Richardson T., Elliott P. \& Roberts R. (2013) The relationship between personal unsecured debt and mental and physical health: a systematic review and meta-analysis. Clinical Psychology Review, 33 (8), 1148-1162.

Schulsinger F. \& Jablensky A. (eds) (1991) The national mental health programme in the United Republic of Tanzania: a report from WHO and DANIDA. Acta Psychiatrica Scandinavica, 83 (Suppl. 364), 132.

United Nations (1996) Prevention of Suicide: Guidelines for the Formulation and Implementation of National Strategies. UN Department of Policy Coordination and Sustainable Development, ST/ESA/245.

United Nations (2000) United Nations Millennium Declaration, Resolution 55/2 Adopted by the General Assembly on 18 September 2000. UN (http://www.un.org/millennium/declaration/ares552e.pdf).

United Nations General Assembly (2015) Resolution 70/1 adopted by the General Assembly on 25 September 2015: Transforming our World: The 2030 Agenda for Sustainable Development. UN (http:// www.un.org/sustainabledevelopment/development-agenda).

World Health Organization (1946) Constitution of the World Health Organization. WHO (http://www.who.int/governance/eb/ who_constitution_en.pdf).

World Health Organization (1978) Declaration of Alma Ata. WHO (http://www.who.int/publications/almaata_declaration_en.pdf).

World Health Organization (2001) The World Health Report 2001 Mental Health: New Understanding, New Hope. WHO (http://www. who.int/whr/2001/en/).

World Health Organization (2007) Everybody's Business: Strengthening Health Systems to Improve Health Outcomes WHO's Framework for Action. WHO (http://www.who.int/healthsystems/ strategy/everybodys_business.pdf).

World Health Organization (2010) World Health Organization Global Code of Practice on the International Recruitment of Health Personnel. WHO (http://apps.who.int/gb/ebwha/pdf_files/WHA63/ A63_R16-en.pdf).

\title{
SPECIAL
} PAPER

\section{Human rights-based approaches to mental health legislation and global mental health}

\author{
Julian Eaton
}

Co-Director, Centre for Global Mental Health, London School of Hygiene and Tropical Medicine, London, UK, email julian.eaton@ cbm.org

Conflicts of interest None.
Globally, established practice in mental health services has tended to be codified into law in ways that are paternalistic, seeking to make decisions for patients that presume 'best interest' and which ultimately place power in the hands of medical authority. The United
Nations Convention on the Rights of Persons with Disabilities (CRPD) - which has been widely ratified globally - challenges these assumptions, instead placing the expressed will and preference of patients as the most important factor in decision-making, including 